\title{
Upregulation of long non-coding RNA CCAT2 indicates a poor prognosis and promotes proliferation and metastasis in intrahepatic cholangiocarcinoma
}

\author{
JIAN-GUO BAI $^{1}$, RUI-FENG TANG ${ }^{1}$, JUN-FENG SHANG $^{2}$, SHUAI QI $^{3}$, GUO-DONG YU $^{4}$ and CHAO SUN ${ }^{1}$ \\ ${ }^{1}$ Department of Hepatobiliary Surgery, The Fourth Hospital of Hebei Medical University, Shijiazhuang, Hebei 050011; \\ ${ }^{2}$ Department of General Surgery, The People's Hospital of Daming, Handan, Hebei 056900; ${ }^{3}$ Second Department of Surgery, \\ The People's Hospital of Luancheng, Shijiazhuang, Hebei 051430; ${ }^{4}$ Department of Hepatobiliary Surgery, \\ The Affiliated Hospital of Hebei University, Baoding, Hebei 071000, P.R. China
}

Received July 24, 2017; Accepted November 2, 2017

DOI: $10.3892 / \mathrm{mmr} .2018 .8518$

\begin{abstract}
Intrahepatic cholangiocarcinoma (IHCC) is an aggressive cancer with a poor survival rate and is the second most common type of primary cancer of the hepatobiliary system. At present, the molecular mechanisms of IHCC initiation and progression remain unclear. Recent evidence has indicated that long non-coding RNAs (lncRNAs) serve a crucial role in cancer development; however, the functional role of lncRNAs in IHCC has not been investigated in detail. In the present study, a marked overexpression of lncRNA colon cancer-associated transcript 2 (CCAT2) was observed in IHCC cell lines and clinical specimens. Statistical analysis of IHCC clinicopathological characteristics and CCAT2 expression data revealed that high CCAT2 expression levels correlated with microvascular invasion, differentiation grade, tumor $(\mathrm{T})$, lymph node $(\mathrm{N})$, metastasis $(\mathrm{M})$ and overall TNM stages of IHCC $(\mathrm{P}<0.05)$. Kaplan-Meier analysis demonstrated that CCAT2 upregulation was associated with poor overall survival and progression-free survival in IHCC. Furthermore, high CCAT2 expression was identified as an independent risk factor of IHCC poor prognosis in both univariate and multivariate Cox regression analyses. The role of CCAT2 in promoting IHCC cell proliferation, motility and invasion was further confirmed with in vitro assays. Therefore, CCAT2 may promote IHCC progression and metastasis, and may be a promising prognostic biomarker and therapeutic target in IHCC.
\end{abstract}

Correspondence to: Dr Chao Sun, Department of Hepatobiliary Surgery, The Fourth Hospital of Hebei Medical University, 12 Jiangkang Road, Shijiazhuang, Hebei 050011, P.R. China E-mail: hbmunisc@126.com

Key words: colon cancer-associated transcript 2, prognosis, proliferation, metastasis, cholangiocarcinoma

\section{Introduction}

Intrahepatic cholangiocarcinoma (IHCC) originates from the biliary epithelial cells within the liver (1) and is the second most common type of primary liver tumor, the first being hepatocellular carcinoma. Although IHCC is a relatively rare cancer, accounting for 10-15\% of primary liver cancers (2), the global incidence of IHCC has increased over the past few decades (1). Currently, surgical resection is the only curative method of IHCC treatment. However, there are no specific markers for IHCC identified that may aid in early diagnosis (3), and patients with IHCC are usually asymptomatic until an advanced stage, with a surgical resection rate of $\sim 30 \%$ (4). Additionally, recurrence is reported in $46-65 \%$ of patients following resection (5), and patients with unresectable IHCC typically succumb within 12-24 months following diagnosis owing to the limited adjuvant therapeutic strategies available (6). Therefore, it is crucial to elucidate the exact molecular mechanisms of IHCC to identify more valuable diagnostic markers and therapeutic targets.

Accumulating evidence has revealed that long non-coding RNAs (lncRNAs) are involved in a broad range of cellular processes, including the regulation of gene expression, genomic imprinting, chromatin modification, transcription and post-translational modification (7). IncRNAs have also been demonstrated to be involved in cancer initiation and development $(8,9)$. A recent study revealed that 1 chNAs are strongly associated with the clinicopathological outcomes and prognosis of various cancers (10). Notably, lncRNAs exhibit cancer and lineage-specific expression patterns, indicating that they may be drivers of cancer biology and may have potential as clinical biomarkers $(10,11)$. The lncRNA colon cancer-associated transcript 2 (CCAT2) has been demonstrated to promote colorectal cancer growth, metastasis and chromosomal instability through the upregulation of MYC and WNT expression (12). CCAT2 is an lncRNA that encompasses the rs6983267 single-nucleotide polymorphism (SNP) located on chromosome 8q24.21. Increased cancer risk from this SNP variant has been linked to several types of cancer, including prostate, ovarian and inflammatory breast cancer $(13,14)$. Mutations in $8 \mathrm{q} 24$ have also been 
frequently detected in biliary cancers and are included in the pancreaticobiliary probe set for early cancer detection (15). A meta-analysis of the ability of CCAT2 to predict metastasis and poor prognosis confirmed that high CCAT2 expression was associated with advanced tumor stage and may predict poor survival in cancers and therefore may serve as a novel prognostic marker and therapeutic target (16). However, to the best of our knowledge, the functional role of CCAT2 in IHCC has not been investigated.

The present study aimed to investigate the expression levels of 1ncRNA CCAT2 in IHCC cells and clinical specimens. The statistical association between CCAT2 levels and IHCC clinicopathological characteristics was calculated to analyze the clinical significance of CCAT2 in IHCC. The contribution of CCAT2 in IHCC prognostic prediction was investigated and the proliferative and invasive ability of IHCC cell with either CCAT2 knockdown or upregulated expression was evaluated by in vitro assay.

\section{Materials and methods}

Patients and tissue samples. IHCC tissues and paired adjacent non-tumorous tissues $(\mathrm{n}=106)$ were collected from the patients with IHCC who underwent curative surgical resection between January 2008 and October 2015 at The Fourth Hospital of Hebei Medical University (Shijiazhuang, China). Tumor and adjacent non-tumorous tissues were isolated. Non-tumorous tissues were obtained from $\geq 1 \mathrm{~cm}$ away from the tumor border and were confirmed to contain no existing tumor cells. Following resection, the collected paired tissue samples were frozen with liquid nitrogen and stored at $-80^{\circ} \mathrm{C}$ until further use. No patients received anticancer therapies prior to surgery. Patients diagnosed with more than two malignances were excluded from the study. Written informed consent was obtained from each patient. This study was approved by The Ethics Committee of The Fourth Hospital of Hebei Medical University (Shijiazhuang, China).

Cell culture and transfection. The IHCC cell lines HUH28, HuCCT1, RBE and HCCC9810 and the immortalized human cholangiocyte-derived cell line H69 were all purchased from The Institute of Biochemistry and Cell Biology of the Chinese Academy of Sciences (Shanghai, China). All cell lines were cultured in RPMI-1640 medium (HuCCT1, HCCC9810 and RBE) or Dulbecco's modified Eagle's medium (DMEM) (HUH28), supplemented with 10\% fetal bovine serum (all from Sigma-Aldrich; Merck KGaA, Darmstadt, Germany) and 1\% penicillin/streptomycin in an atmosphere of $5 \% \mathrm{CO}_{2}$ at $37^{\circ} \mathrm{C}$.

IncRNA CCAT2 overexpression vector (pcDNA3.1CCAT2), control vector (pcDNA3.1-vector) and non-targeting small interfering (si)RNA negative control (siNC) were all purchased from Genewiz, Inc. (South Plainfield, NJ, USA). CCAT2 siRNA (iCCAT2.1 and siCCAT2.2) were designed using the Custom RNAi Design Tool on the Integrated DNA Technologies (IDT) website (http://sg.idtdna.com/site) and synthesized by Genewiz, Inc. Transfection was performed with Lipofectamine $^{\circledR} 2000$ (Invitrogen; Thermo Fisher Scientific, Inc., Waltham, MA, USA), according to the manufacturer's instructions. Subsequent experiments were performed $24 \mathrm{~h}$ after transfection.
Reverse transcription quantitative-polymerase chain reaction (RT-qPCR). TRIzol reagent (Invitrogen; Thermo Fisher Scientific, Inc.) was used to extract total RNA from clinical specimens or cultured cells, according to the manufacturer's instructions. The concentration and purity of the RNA were determined with a NanoDrop 1000 spectrophotometer (Thermo Fisher Scientific, Inc.). cDNA was reverse transcribed using $2 \mu \mathrm{g}$ extracted RNA with the PrimeScript One-Step RT-PCR kit (Takara Biotechnology Co., Ltd., Dalian, China). qPCR was performed using a SYBR PrimeScript RT-PCR kit (Takara Biotechnology Co., Ltd.) with the Mx3005P qPCR System (Agilent Technologies, Inc., Santa Clara, CA, USA), according to the manufacturer's instructions. The PCR cycling conditions were as follows: initial denaturation at $95^{\circ} \mathrm{C}$ for $5 \mathrm{~min}, 40$ cycles of denaturation at $95^{\circ} \mathrm{C}$ for $30 \mathrm{sec}$, annealing at $50^{\circ} \mathrm{C}$ for $30 \mathrm{sec}$ and extension at $72^{\circ} \mathrm{C}$ for $30 \mathrm{sec}$. The expression of lncRNA CCAT2 from tissue samples or cultured cells was normalized to GAPDH and compared using the $2^{-\Delta \Delta \mathrm{Cq}}$ method (17). The primer sequences were: CCAT2 forward, 5'-CCCTGGTCAAATTGCTTAACCT-3' and reverse, 5'-TTA TTCGTCCCTTTTTATGGAT-3'; GADPH forward, 5'-ACC CACTCCTCCACCTTTGAC-3' and reverse, 5'-TGTTGCTGT AGCCAAATTCGTT-3'.

MTT assay. Cells (2,000/well) were seeded into 96-well plates for incubation at $37^{\circ} \mathrm{C}$, and MTT $(10 \mu 1,10 \mathrm{mg} / \mathrm{ml})$ was added to the medium at the indicated time $(0,24,48,72$ and $96 \mathrm{~h}$ following the initial incubation). The plates were incubated for another $4 \mathrm{~h}$ at $37^{\circ} \mathrm{C}$, and dimethylsulfoxide (100 $\left.\mu \mathrm{l}\right)$ was added to dissolve the purple formazan crystals. The absorbance was subsequently measured by a microplate spectrophotometer (Dynex Technologies, Inc., Sullyfield, VA, USA) at a wavelength of $490 \mathrm{~nm}$. Each assay was conducted in triplicate and repeated at least three times.

Colony formation assay. Cells (1,500 cells/dish) were seeded in $6 \mathrm{~cm}$ dishes and incubated in an atmosphere of $5 \% \mathrm{CO}_{2}$ at $37^{\circ} \mathrm{C}$ for 7 days until the colonies were large enough to be clearly discerned. Colonies were defined as groups of $>50$ cells and were counted by light microscopy (x10). Each assay was conducted in triplicate and repeated at least three times.

Transwell and Matrigel assay. Cell migratory ability was evaluated using a Transwell system (pore size, $8.0 \mu \mathrm{m}$; Sigma-Aldrich; Merck KGaA) Cells $\left(3 \times 10^{4}\right)$ were suspended in serum-free medium (RPMI-1640 medium for HuCCT1, HCCC9810 and RBE; DMEM medium for HUH28) and plated in the upper chamber of the Transwell system, and the lower chamber was filled with medium containing $10 \%$ FBS. Following incubation for $24 \mathrm{~h}$ at $37^{\circ} \mathrm{C}$, the cells in the upper chamber were removed and the cells in the lower chamber were fixed by pure cold methanol $\left(-4^{\circ} \mathrm{C}\right)$ for $30 \mathrm{~min}$ and subjected to Giemsa staining (1:10 dilution) for another $30 \mathrm{~min}$ at room temperature. Cells were subsequently counted with a light microscope (x10). The Matrigel assay procedure to assess cell invasive ability was identical to the Transwell assay, except the Transwell membrane was precoated with Matrigel (BD Biosciences, Franklin Lakes, NJ, USA). All experiments were performed in triplicate. 
$\mathbf{A}$

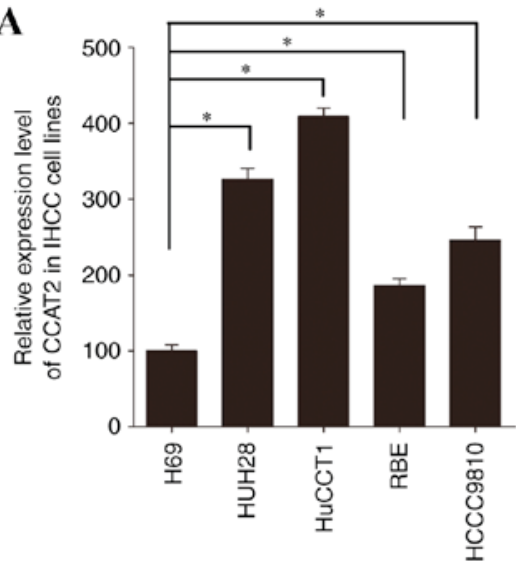

C

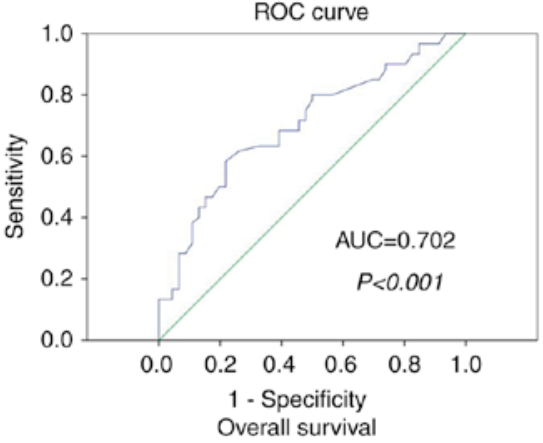

$\mathbf{E}$

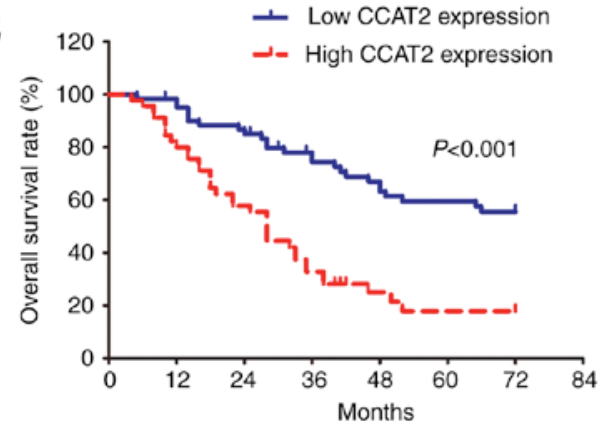

B

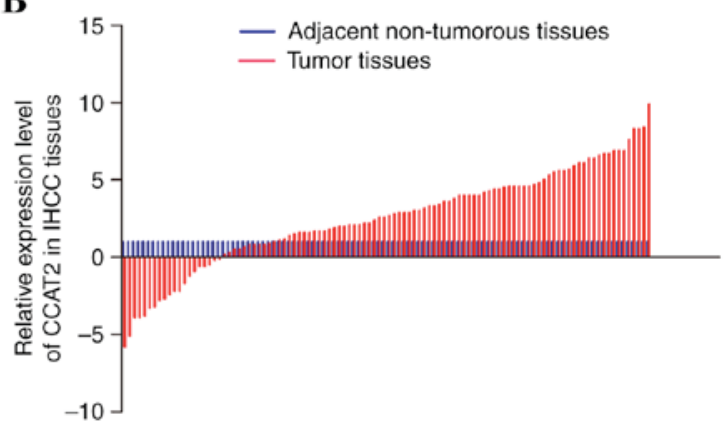

D

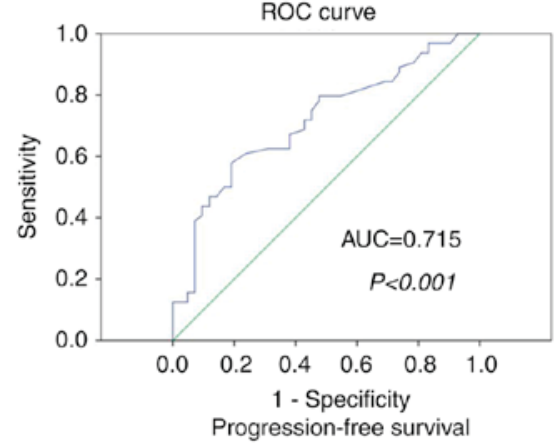

F

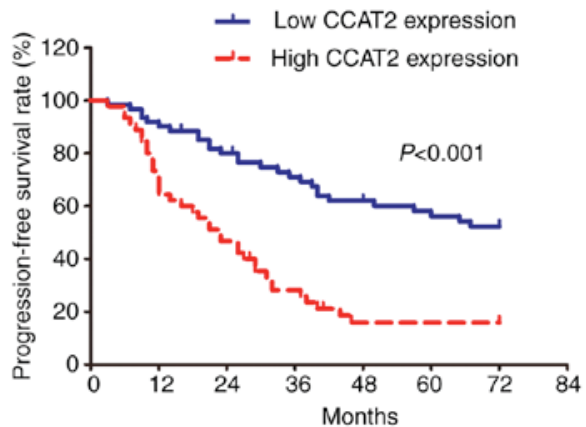

Figure 1. CCAT2 expression is upregulated in IHCC and correlated with IHCC OS and PFS. (A) RT-qPCR was used to investigate the expression of CCAT2 in IHCC cell lines and the immortalized human cholangiocyte-derived cell line H69; ${ }^{*} \mathrm{P}<0.05$. (B) The relative expression of CCAT2 in IHCC tissues was analyzed by RT-qPCR. Red lines indicate CCAT2 expression in IHCC tissues; blue lines indicate the paired adjacent non-tumorous tissue expression of CCAT2. (C and D) ROC curves were utilized to define the cut-off points of high or low CCAT2 expression for the (C) OS and (D) PFS of patients with IHCC. (E and F) Kaplan-Meier analysis and the log-rank test were performed to investigate the (E) OS and (F) PFS differences between the CCAT2 low and high expression groups; $\mathrm{P}<0.001$ based on the log-rank test. AUC, area under the curve; CCAT2, colon cancer associated transcript 2; IHCC, intrahepatic cholangiocarcinoma; OS, overall survival; PFS, progression-free survival; ROC, receiver operating characteristic; RT-qPCR, reverse transcription quantitative-polymerase chain reaction.

Statistical analysis. Statistical analysis was performed using the SPSS 17.0 software package (SPSS, Inc., Chicago, IL, USA). All data is expressed as the mean \pm standard deviation. For statistical analysis, categorical variables were compared using the $\chi^{2}$ test and the Student's t-test was performed to compare the differences between continuous data. One-way analysis of variance and Bonferroni correction test were used to compare multiple groups. The overall survival (OS) and progression free survival (PFS) rate were analyzed with the Kaplan-Meier method and differences between groups were assessed with the log-rank test. The significance of the survival data was evaluated using univariate and multivariate Cox regression methods. The receiver-operating characteristic (ROC) curve was adopted to define the cut-off score for discriminating the specimens with high or low CCAT2 expression. The point on the curve with the shortest distance to the coordinate $(0,1)$ was selected as the threshold value to classify cases as high expression or low expression. $\mathrm{P}<0.05$ was considered to indicate a statistically significant difference.

\section{Results}

lncRNA CCAT2 is overexpressed in IHCC. The analysis of lncRNA CCAT2 expression in IHCC cells lines by RT-qPCR assay revealed that CCAT2 expression was upregulated in IHCC cell lines compared with normal biliary epithelial cells (Fig. 1A). CCAT2 expression was higher in $70.8 \%$ $(75 / 106)$ of IHCC samples compared with the paired adjacent 
Table I. Correlation between long non-coding RNA CCAT2 expression and the clinicopathological characteristics of intrahepatic cholangiocarcinoma.

\begin{tabular}{lccc}
\hline & No. of & CCAT2 & \\
Parameter & patients & High/Low & P-value \\
\hline
\end{tabular}

\begin{tabular}{lccc}
\hline Age (years) & & & 0.204 \\
$<60$ & 50 & $18 / 32$ & \\
$\geq 60$ & 56 & $27 / 29$ & \\
Sex & & & 0.620 \\
Male & 78 & $32 / 46$ &
\end{tabular}

Female

28

$13 / 15$

$\mathrm{HBeAg}$

Negative

72

Positive

34

$31 / 41$

HBsAg

Negative

$14 / 20$

Positive

63

$\mathrm{HCV}$

Negative

Positive

19

CA19-9 (U/ml)

$<37$

$\geq 37$

No. of tumors

Single
Multiple

Microvascular invasion

No

Cirrhosis

No

Encapsulation

No

Complete

Differentiation grade

Low + intermediate

High

Tumor size $(\mathrm{cm})$

$<5$
$\geq 5$

T stage

$\mathrm{T} 1+\mathrm{T} 2$

$\mathrm{T} 3+\mathrm{T} 4$

$\mathrm{N}$ stage

No

$\mathrm{N} 1$

M stage

Table I. Continued

\begin{tabular}{|c|c|c|c|}
\hline \multirow[b]{2}{*}{ Parameter } & \multirow{2}{*}{$\begin{array}{l}\text { No. of } \\
\text { patients }\end{array}$} & CCAT2 & \multirow[b]{2}{*}{ P-value } \\
\hline & & High/Low & \\
\hline TNM stage & & & $<0.001$ \\
\hline $\mathrm{I}+\mathrm{II}$ & 55 & $13 / 42$ & \\
\hline III + IV & 51 & $32 / 19$ & \\
\hline
\end{tabular}

$\mathrm{HBeAg}$, hepatitis B viral protein; HBsAg, hepatitis B surface antigen; HCV, hepatitis C virus; CA19-9, cancer antigen 19-9; T, tumor; $\mathrm{N}$, lymph node; $\mathrm{M}$, metastasis.

0.855

0.919

0.290

0.327

0.851

$<0.001$

0.179

0.821

0.040

0.326

0.012

$<0.001$

0.045

non-tumorous tissues (Fig. 1B). Further statistical analysis confirmed that IHCC tissues had significantly higher relative CCAT2 expression compared with paired adjacent non-tumorous tissues ( 1 vs. $2.52 \pm 3.17$; $\mathrm{P}<0.001$; Fig. 1B), which indicated that lncRNA CCAT2 may be oncogenic in IHCC.

Expression level of IncRNA CCAT2 is correlated with IHCC clinical progression. To better define the value of CCAT2 expression level in predicting the prognosis of patients with IHCC, the ROC curve was adopted to identify the optimal cut-off score for high/low CCAT2 expression (Fig. 1C and D). The area under the curves were 0.702 and 0.715 for OS and PFS, respectively, which suggested that CCAT2 may be a useful biomarker for the prognostic prediction of IHCC $(\mathrm{P}<0.001)$. The cutoff score was 4.4 for both OS and PFS.

To investigate the clinical significance of CCAT2 in IHCC, the association between CCAT2 expression and clinicopathological characteristics was statistically analyzed. High CCAT2 expression was revealed to be associated with microvascular invasion $(\mathrm{P}<0.001)$, differentiation grade $(\mathrm{P}=0.040)$, and tumor $(\mathrm{T} ; \mathrm{P}=0.012)$, lymph node $(\mathrm{N} ; \mathrm{P}<0.001)$, metastasis $(\mathrm{M} ; \mathrm{P}=0.045)$ and combined TNM $(\mathrm{P}<0.001)$ stages of IHCC (Table I). However, other clinicopathological parameters including age, sex, hepatitis B viral protein, hepatitis B surface antigen, hepatitis $C$ virus, cancer antigen 19-9, tumor number, cirrhosis and encapsulation were not indicated to be statistically significant $(\mathrm{P}>0.05$; Table I). These results suggested that CCAT2 overexpression may be associated with the development of IHCC.

CCAT2 is a prognostic marker and an independent risk factor for IHCC prognosis. The significance of CCAT2 in the prediction of prognosis was evaluated by Kaplan-Meier analysis. Patients with high CCAT2 expression were demonstrated to have a lower OS rate $(\mathrm{P}<0.001)$ and a shorter $\mathrm{PFS}$ period $(\mathrm{P}<0.001$; Fig. 1E and F $)$

Furthermore, univariate analysis demonstrated that high CCAT2 expression was a risk factor for OS [hazard ratio $(\mathrm{HR})=3.184 ; 95 \%$ confidence interval $(\mathrm{CI})=1.882-5.385$; $\mathrm{P}<0.001]$ and for PFS $(\mathrm{HR}=2.926 ; 95 \% \mathrm{CI}=1.771-4.834$; $\mathrm{P}<0.001$ ) of patients with IHCC (Table II). Multivariate analysis also identified high CCAT2 expression as an independent risk factor of $\mathrm{OS}(\mathrm{HR}=1.894$; 95\% $\mathrm{CI}=1.060-3.384$; 
Table II. Univariate analysis of clinicopathological features for overall survival and progression-free survival of patients with intrahepatic cholangiocarcinoma.

\begin{tabular}{|c|c|c|c|c|c|c|}
\hline \multirow[b]{2}{*}{ Parameter } & \multicolumn{3}{|c|}{ Overall survival } & \multicolumn{3}{|c|}{ Progression-free survival } \\
\hline & HR & $95 \% \mathrm{CI}$ & P-value & HR & $95 \% \mathrm{CI}$ & P-value \\
\hline \multicolumn{7}{|l|}{ Age (years) } \\
\hline$<60$ vs. $\geq 60$ & 1.255 & $0.750-2.100$ & 0.387 & 1.261 & $0.766-2074$ & 0.362 \\
\hline \multicolumn{7}{|l|}{ Sex } \\
\hline Female vs. male & 0.596 & $0.322-1.104$ & 0.100 & 0.609 & $0.336-1.103$ & 0.102 \\
\hline \multicolumn{7}{|l|}{ HBeAg } \\
\hline Positive vs. negative & 0.824 & $0.470-1.446$ & 0.500 & 0.873 & $0.510-1.493$ & 0.619 \\
\hline \multicolumn{7}{|l|}{ HBsAg } \\
\hline Positive vs. negative & 1.252 & $0.746-2.101$ & 0.395 & 1.218 & $0.739-2.008$ & 0.439 \\
\hline \multicolumn{7}{|l|}{$\mathrm{HCV}$} \\
\hline Positive vs. negative & 1.707 & $0.938-3.108$ & 0.080 & 1.788 & $1.002-3.190$ & 0.049 \\
\hline \multicolumn{7}{|l|}{ CA19-9 (U/ml) } \\
\hline$<37$ vs. $\geq 37$ & 0.919 & $0.551-1.533$ & 0.747 & 0.857 & $0.523-1.402$ & 0.538 \\
\hline \multicolumn{7}{|l|}{ Tumor number } \\
\hline Single vs. multiple & 1.535 & $0.830-2.839$ & 0.172 & 1.495 & $0.813-2.751$ & 0.196 \\
\hline \multicolumn{7}{|l|}{ Microvascular invasion } \\
\hline Yes vs. no & 0.485 & $0.288-0.816$ & 0.006 & 0.512 & $0.307-0.853$ & 0.010 \\
\hline \multicolumn{7}{|l|}{ Cirrhosis } \\
\hline Yes vs. no & 1.428 & $0.848-2.405$ & 0.181 & 1.360 & $0.823-2.249$ & 0.231 \\
\hline \multicolumn{7}{|l|}{ Encapsulation } \\
\hline Complete vs. none & 1.023 & $0.605-1.730$ & 0.931 & 1.042 & $0.628-1.730$ & 0.872 \\
\hline \multicolumn{7}{|l|}{ Differentiation } \\
\hline Low + intermediate vs. high & 1.945 & $1.155-3.276$ & 0.012 & 2.133 & $1.283-3.547$ & 0.003 \\
\hline \multicolumn{7}{|l|}{ Tumor size $(\mathrm{cm})$} \\
\hline$<5$ vs. $\geq 5$ & 1.351 & $0.812-2.250$ & 0.247 & 1.195 & $0.731-1.953$ & 0.478 \\
\hline \multicolumn{7}{|l|}{ T stage } \\
\hline $\mathrm{T} 1+\mathrm{T} 2$ vs. $\mathrm{T} 3+\mathrm{T} 4$ & 2.337 & $1.378-3.964$ & 0.002 & 2.353 & $1.406-3.936$ & 0.001 \\
\hline \multicolumn{7}{|l|}{$\mathrm{N}$ stage } \\
\hline N0 vs. N1 & 1.526 & $1.190-1.957$ & 0.001 & 1.533 & $1.201-1.956$ & 0.001 \\
\hline \multicolumn{7}{|l|}{ M stage } \\
\hline M0 vs. M1 & 5.364 & $2.250-12.788$ & $<0.001$ & 4.643 & $1.958-11.011$ & $<0.001$ \\
\hline \multicolumn{7}{|l|}{ TNM stage } \\
\hline I + II vs. III + IV & 4.647 & $2.613-8.262$ & $<0.001$ & 4.617 & $2.656-8.025$ & $<0.001$ \\
\hline \multicolumn{7}{|l|}{ CCAT2 } \\
\hline Low vs. high & 3.184 & $1.882-5.385$ & $<0.001$ & 2.926 & $1.771-4.834$ & $<0.001$ \\
\hline
\end{tabular}

CA19-9, cancer antigen 19-9; CCAT2, colon cancer associated transcript 2; CI, confidence interval; HBeAg, hepatitis B viral protein; HBsAg, hepatitis B surface antigen; $\mathrm{HCV}$, hepatitis $\mathrm{C}$ virus; $\mathrm{HR}$, hazard ratio; M, metastasis; N, lymph node; T, tumor.

$\mathrm{P}=0.031)$ and $\mathrm{PFS}(\mathrm{HR}=2.134 ; 95 \% \mathrm{CI}=1.232-3.699 ; \mathrm{P}=0.007)$ of patients with IHCC (Table III). Thus, lncRNA CCAT2 may be useful as a prognostic marker for OS and PFS of patients with IHCC.

CCAT2 promotes the proliferation and metastasis of IHCC cells. To extend our understanding on the role of CCAT2 in IHCC, in vitro assays were performed in IHCC cells with either CCAT2 silencing and overexpression (Fig. 2A and B). As CCAT2 expression was relatively high in HuCCT1 cells and low in RBE cells (Fig. 1A) these cell lines were used to confirm the effects of siRNA-induced CCAT2 silencing and CCAT2 overexpression, respectively (Fig. 2A and B, respectively). The MTT assay revealed that the proliferative ability of HuCCT1 cells was significantly decreased following transfection with siCCAT2.1 and siCCAT2.2 compared with cells transfected 
Table III. Multivariate analysis of clinicopathological features for overall survival and progression-free survival of patients with intrahepatic cholangiocarcinoma.

\begin{tabular}{|c|c|c|c|c|c|c|}
\hline \multirow[b]{2}{*}{ Parameter } & \multicolumn{3}{|c|}{ Overall survival } & \multicolumn{3}{|c|}{ Progression-free survival } \\
\hline & HR & $95 \% \mathrm{CI}$ & P-value & HR & $95 \% \mathrm{CI}$ & P-value \\
\hline $\begin{array}{l}\mathrm{HCV} \\
\text { Positive vs. negative }\end{array}$ & - & - & - & 2.091 & $1.154-3.788$ & 0.015 \\
\hline $\begin{array}{l}\text { Microvascular invasion } \\
\text { Yes vs. no }\end{array}$ & 0.485 & $0.279-0.843$ & 0.010 & 0.502 & $0.292-0.863$ & 0.013 \\
\hline $\begin{array}{l}\text { Differentiation } \\
\text { Low + intermediate vs. high }\end{array}$ & 0.938 & $0.503-1.751$ & 0.842 & 1.107 & $0.606-2.021$ & 0.742 \\
\hline $\begin{array}{l}\text { T stage } \\
\mathrm{T} 1+\mathrm{T} 2 \text { vs. } \mathrm{T} 3+\mathrm{T} 4\end{array}$ & 0.607 & $0.299-1.231$ & 0.166 & 0.527 & $0.261-1.063$ & 0.074 \\
\hline $\begin{array}{l}\text { N stage } \\
\text { N0 vs. N1 }\end{array}$ & 0.890 & $0.517-1.529$ & 0.672 & 0.767 & $0.465-1.264$ & 0.298 \\
\hline $\begin{array}{l}\text { M stage } \\
\text { M0 vs. M1 }\end{array}$ & 3.078 & $1.193-7.943$ & 0.020 & 2.642 & $1.035-6.746$ & 0.042 \\
\hline $\begin{array}{l}\text { TNM stage } \\
\text { I + II vs. III + IV }\end{array}$ & 4.972 & $2.108-12.250$ & $<0.001$ & 5.797 & $2.431-13.824$ & $<0.001$ \\
\hline $\begin{array}{l}\text { CCAT2 } \\
\text { Low vs. high }\end{array}$ & 1.894 & $1.060-3.384$ & 0.031 & 2.134 & $1.232-3.699$ & 0.007 \\
\hline
\end{tabular}

CCAT2, colon cancer associated transcript 2; CI, confidence interval; HCV, hepatitis C virus; HR, hazard ratio; M, metastasis; N, lymph node; $\mathrm{T}$, tumor.

with the siNC (Fig. 2C; $\mathrm{P}<0.05$ ). The colony formation assay also revealed that CCAT2 silencing in HuCCT1 cells significantly decreased colony numbers compared with the siNC-transfected cells (Fig. 2D; P<0.05). In addition, CCAT2 overexpression significantly increased the proliferative ability (Fig. 2E; P<0.05) and the number of colonies (Fig. 2F; $\mathrm{P}<0.05$ ) of $\mathrm{RBE}$ cells compared with cells transfected with the empty vector.

The migratory and invasive abilities of HuCCT1 cells were significantly inhibited in cells transfected with either CCAT2 siRNA compared with siNC-transfected cells (Fig. 3A; $\mathrm{P}<0.05)$ By contrast, the migratory and invasive abilities were significantly increased in RBE cells overexpressing CCAT2 compared with vector control cells (Fig. 3B; $\mathrm{P}<0.05$ ). These data suggested that CCAT2 may promote proliferation and metastasis of IHCC cells.

\section{Discussion}

Previous studies have reported the involvement of lncRNA CCAT2 in the development and metastasis of a number of cancers. For example, Ling et al (12) reported that CCAT2 expression was markedly increased in microsatellite-stable colorectal cancer and that CCAT2 promoted tumor growth, metastasis and chromosomal instability through the regulation of MYC and WNT expression. Qiu et al (18) demonstrated that CCAT2 was upregulated in non-small cell lung cancer and increased the proliferation and metastasis of tumor cells. The functional role of CCAT2 in promoting tumor growth and metastasis has also been demonstrated in esophageal squamous cell carcinoma, glioma, breast cancer, hepatocellular carcinoma and ovarian cancer (19-22). Furthermore, a previous meta-analysis revealed that high CCAT2 expression was significantly correlated with $\mathrm{OS}(\mathrm{HR}=2.30 ; 95 \% \mathrm{CI}=1.62-3.25$; $\mathrm{P}<0.001)$ and PFS $(\mathrm{HR}=2.76 ; 95 \% \mathrm{CI}=1.74-4.37 ; \mathrm{P}<0.001)$ in various cancers (16).

The present study confirmed that CCAT2 was overexpressed in IHCC cell lines and tissues. Statistical analysis of CCAT2 expression and IHCC clinicopathological features revealed that high CCAT2 expression was associated with microvascular invasion, differentiation grades, T, N, M and TNM stages of IHCC $(\mathrm{P}<0.05)$. Based on these data and results from in vitro assays, it was hypothesized that CCAT2 may promote IHCC progression and metastasis. Survival analysis demonstrated that patients with high CCAT2 expression had a lower OS rate and shorter PFS period $(\mathrm{P}<0.05)$. Furthermore, high CCAT2 expression was identified as an independent risk factor of poor $\mathrm{OS}(\mathrm{HR}=3.184$; 95\% $\mathrm{CI}=1.882-5.385$; $\mathrm{P}<0.001)$ and $\mathrm{PFS}(\mathrm{HR}=2.926 ; 95 \% \mathrm{CI}=1.771-4.834 ; \mathrm{P}<0.001)$ of patients with IHCC in the multivariate Cox regression analysis.

Mechanistically, several studies have concentrated on identifying the downstream mechanisms of CCAT2 function. Previous studies reported that the mechanism of CCAT2 in promoting cancer development is mainly due to the activation of WNT signaling by enhancing the transcriptional activity of transcription factor 7-like 2 and the subsequent increase in MYC expression (22-24). Another study reported that CCAT2 


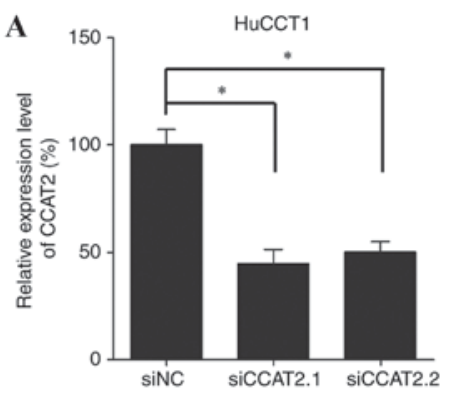

C

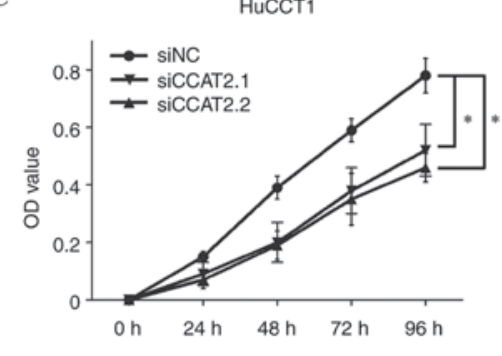

$\mathbf{E}$

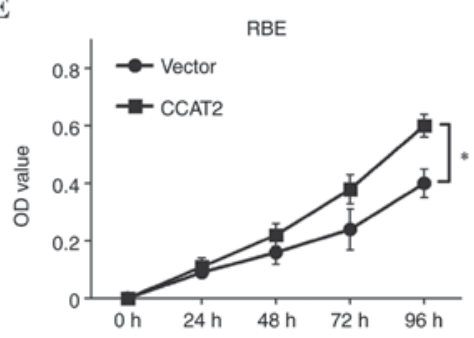

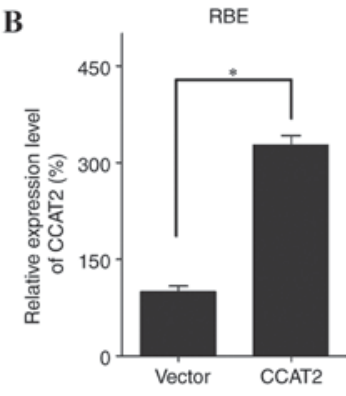

D
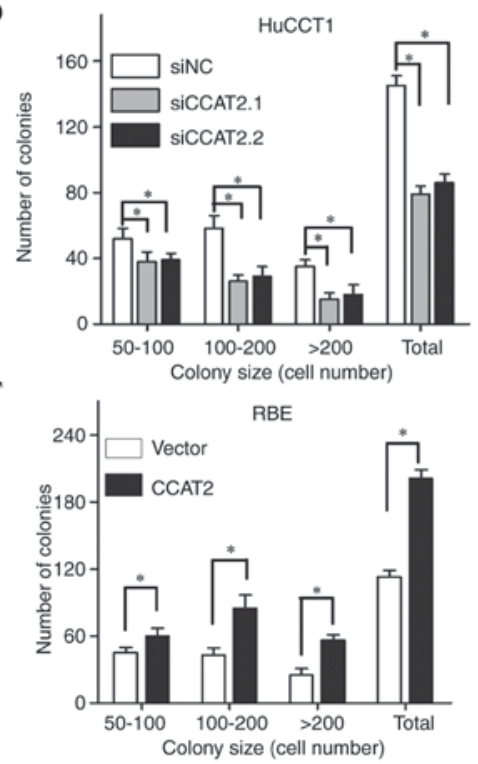

Figure 2. CCAT2 expression increases the proliferative ability of IHCC cells. (A) CCAT2 expression was analyzed by RT-qPCR in HuCCT1 cells transfected with siNC, siCCAT2.1 or siCCAT2.2. (B) CCAT2 expression was analyzed by RT-qPCR in RBE cells transfected with empty control vector or CCAT2 overexpression vector. (C) The MTT assay and (D) a colony formation assay were performed to investigate the proliferative ability of HuCCT1 cells transfected with CCAT2 siRNAs. (E) The MTT assay and (F) a colony formation assay were also performed to investigate the proliferative ability of RBE cells overexpressing CCAT2. "P<0.05 vs. siNC or empty vector. CCAT2, colon cancer associated transcript 2; IHCC, intrahepatic cholangiocarcinoma; OD, optical density; RT-qPCR, reverse transcription-quantitative polymerase chain reaction; siCCAT, small interfering RNA against CCAT2; siNC, non-targeting small interfering RNA.
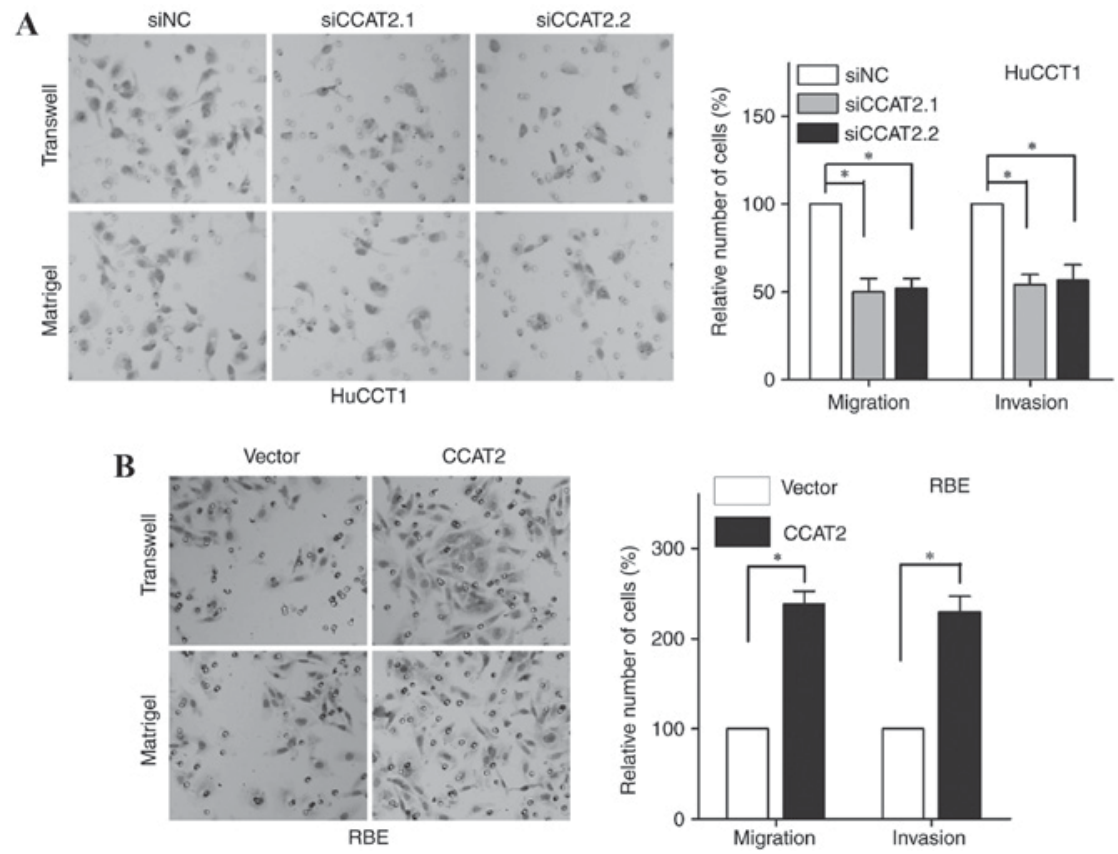

Figure 3. CCAT2 promotes migration and invasion of IHCC cells. (A and B) Representative images and quantification of the Matrigel and Transwell assays performed to assess the migratory and invasive abilities of (A) HuCCT1 cells transfected with siRNAs directed against CCAT2 and (B) RBE cells transfected with a CCAT2 overexpression vector; " $\mathrm{P}<0.05$ vs. siNC or empty vector. CCAT2, colon cancer associated transcript 2; IHCC, intrahepatic cholangiocarcinoma; siNC, non-targeting small interfering RNA; siCCAT, small interfering RNA against CCAT2. 
regulates epithelial ovarian cancer progression by functioning as a competing endogenous RNA, or sponge, and negatively targeting miR-424 (25). Further investigations are required to fully understand the mechanisms of CCAT2 function and its contribution to IHCC progression and metastasis.

In conclusion, results from the present study demonstrated that IncRNA CCAT2 expression was upregulated in IHCC and this high expression level may be correlated with IHCC progression and metastasis. High CCAT2 expression predicted a poor OS rate and shorter PFS period. CCAT2 overexpression was also an independent risk factor for both OS and PFS. The functional role of CCAT2 in facilitating proliferation and metastasis of IHCC cells was further confirmed in in vitro assays and CCAT2 may be a promising prognostic biomarker and therapeutic target in IHCC.

\section{References}

1. Razumilava N and Gores GJ: Cholangiocarcinoma. Lancet 383: 2168-2179, 2014.

2. Aljiffry M, Abdulelah A, Walsh M, Peltekian K, Alwayn I and Molinari M: Evidence-based approach to cholangiocarcinoma: A systematic review of the current literature. J Am Coll Surg 208: 134-147, 2009.

3. Sia D, Tovar V, Moeini A and Llovet JM: Intrahepatic cholangiocarcinoma: Pathogenesis and rationale for molecular therapies. Oncogene 32: 4861-4870, 2013.

4. Endo I, Gonen M, Yopp AC, Dalal KM, Zhou Q, Klimstra D, D'Angelica M, DeMatteo RP, Fong Y, Schwartz L, et al: Intrahepatic cholangiocarcinoma: Rising frequency, improved survival, and determinants of outcome after resection. Ann Surg 248: 84-96, 2008.

5. Dodson RM, Weiss MJ, Cosgrove D, Herman JM, Kamel I, Anders R, Geschwind JF and Pawlik TM: Intrahepatic cholangiocarcinoma: Management options and emerging therapies. J Am Coll Surg 217: 736-750.e4, 2013.

6. Sirica AE, Dumur CI, Campbell DJ, Almenara JA, Ogunwobi OO and Dewitt JL: Intrahepatic cholangiocarcinoma progression: Prognostic factors and basic mechanisms. Clin Gastroenterol Hepatol 7 (11 Suppl): S68-S78, 2009.

7. Isin $M$ and Dalay $N$ : 1ncRNAs and neoplasia. Clin Chim Acta 444: 280-288, 2015.

8. Sahu A, Singhal U and Chinnaiyan AM: Long noncoding RNAs in cancer: From function to translation. Trends Cancer 1: 93-109, 2015.

9. Bartonicek N, Maag JL and Dinger ME: Long noncoding RNAs in cancer: Mechanisms of action and technological advancements. Mol Cancer 15: 43, 2016.

10. Fatima R, Akhade VS, Pal D and Rao SM: Long noncoding RNAs in development and cancer: Potential biomarkers and therapeutic targets. Mol Cell Ther 3: 5, 2015.

11. Schmitt AM and Chang HY: Long noncoding RNAs in cancer pathways. Cancer Cell 29: 452-463, 2016.
12. Ling H, Spizzo R, Atlasi Y, Nicoloso M, Shimizu M, Redis RS Nishida N, Gafà R, Song J, Guo Z, et al: CCAT2, a novel noncoding RNA mapping to $8 \mathrm{q} 24$, underlies metastatic progression and chromosomal instability in colon cancer. Genome Res 23: 1446-1461, 2013.

13. Ghoussaini M, Song H, Koessler T, Al Olama AA, Kote-Jarai Z, Driver KE, Pooley KA, Ramus SJ, Kjaer SK, Hogdall E, et al: Multiple loci with different cancer specificities within the 8q24 gene desert. J Natl Cancer Inst 100: 962-966, 2008.

14. Bertucci F, Lagarde A, Ferrari A, Finetti P, Charafe-Jauffret E, Van Laere S, Adelaide J, Viens P, Thomas G, Birnbaum D and Olschwang S: 8q24 cancer risk allele associated with major metastatic risk in inflammatory breast cancer. PLoS One 7: e37943, 2012

15. Barr Fritcher EG, Voss JS, Brankley SM, Campion MB, Jenkins SM, Keeney ME, Henry MR, Kerr SM, Chaiteerakij R, Pestova EV, et al: An optimized set of fluorescence in situ hybridization probes for detection of pancreatobiliary tract cancer in cytology brush samples. Gastroenterology 149: 1813-1824.e1, 2015.

16. Fan YH, Fang H, Ji CX, Xie H, Xiao B and Zhu XG: Long noncoding RNA CCAT2 can predict metastasis and poor prognosis: A meta-analysis. Clin Chim Acta 466: 120-126, 2017.

17. Livak KJ and Schmittgen TD: Analysis of relative gene expression data using real-time quantitative PCR and the 2(-Delta Delta C(T)) method. Methods 25: 402-408, 2001.

18. Qiu M, Xu Y, Yang X, Wang J, Hu J, Xu L and Yin R: CCAT2 is a lung adenocarcinoma-specific long non-coding RNA and promotes invasion of non-small cell lung cancer. Tumour Biol 35: 5375-5380, 2014.

19. Huang S, Qing C, Huang Z and Zhu Y: The long non-coding RNA CCAT2 is up-regulated in ovarian cancer and associated with poor prognosis. Diagn Pathol 11: 49, 2016.

20. Zhou N, Si Z, Li T, Chen G, Zhang Z and Qi H: Long non-coding RNA CCAT2 functions as an oncogene in hepatocellular carcinoma, regulating cellular proliferation, migration and apoptosis. Oncol Lett 12: 132-138, 2016.

21. Wang J, Qiu M, Xu Y, Li M, Dong G, Mao Q, Yin R and $\mathrm{Xu}$ L: Long noncoding RNA CCAT2 correlates with smoking in esophageal squamous cell carcinoma. Tumour Biol 36: 5523-5528, 2015.

22. Zeng J, Du T, Song Y, Gao Y, Li F, Wu R, Chen Y, Li W, Zhou H, Yang Y and Pei Z: Knockdown of long noncoding RNA CCAT2 inhibits cellular proliferation, invasion, and epithelial-mesenchymal transition in glioma cells. Oncol Res 25: 913-921, 2016.

23. Kasagi Y, Oki E, Ando K, Ito S, Iguchi T, Sugiyama M, Nakashima Y, Ohgaki K, Saeki H, Mimori K and Maehara Y: The expression of CCAT2, a novel long noncoding RNA transcript, and rs6983267 single-nucleotide polymorphism genotypes in colorectal cancers. Oncology 92: 48-54, 2017.

24. Cai Y, He J and Zhang D: Long noncoding RNA CCAT2 promotes breast tumor growth by regulating the Wnt signaling pathway. Onco Targets Ther 8: 2657-2664, 2015.

25. Hua F, Li CH, Chen XG and Liu XP: Long noncoding RNA CCAT2 knockdown suppresses tumorous progression by sponging miR-424 in epithelial ovarian vancer. Oncol Res: May 21, 2017 (Epub ahead of print). 